\title{
Correction to: Detection of QTL for apple fruit acidity and sweetness using sensorial evaluation in multiple pedigreed full-sib families
}

\author{
Marijn Rymenants ${ }^{1,2} \cdot$ Eric van de Weg ${ }^{3} \cdot$ Annemarie Auwerkerken $^{1} \cdot$ Inge De Wit ${ }^{1} \cdot$ Andrzej Czech $^{4} \cdot$ Bart Nijland $^{4}$. \\ Henri Heuven ${ }^{4}$. Nico De Storme ${ }^{2}$. Wannes Keulemans ${ }^{2}$ \\ Published online: 15 December 2020 \\ (C) Springer-Verlag GmbH Germany, part of Springer Nature 2020
}

Correction to: Tree Genetics \& Genomes (2020) 16:71 https://doi.org/10.1007/s11295-020-01466-8

In the original publication, the positions of the SNP markers from the 50K SNP array are given according to GDDH13 v1.0 version of the apple reference genome and not according to GDDH13 v1.1 version as stated in the original publication.

Publisher's note Springer Nature remains neutral with regard to jurisdictional claims in published maps and institutional affiliations.

The online version of the original article can be found at https://doi.org/ $10.1007 / \mathrm{s} 11295-020-01466-8$

Marijn Rymenants

marijn@better3fruit.com

Better3fruit N.V, Steenberg 36, B-3202 Rillaar, Belgium

2 Laboratory for Plant Genetics and Crop Improvement, KU Leuven, Willem de Croylaan 42, B-3001 Leuven, Belgium

3 Department of Plant Breeding, Wageningen University and Research, Wageningen, The Netherlands

4 Genetwister Technologies BV, Wageningen, The Netherlands 